REVIEW ARTICLE

T. Krings

S. Geibprasert

\title{
Spinal Dural Arteriovenous Fistulas
}

\begin{abstract}
SUMMARY: Spinal dural arteriovenous (AV) fistulas are the most commonly encountered vascular malformation of the spinal cord and a treatable cause for progressive para- or tetraplegia. They most commonly affect elderly men and are classically found in the thoracolumbar region. The AV shunt is located inside the dura mater close to the spinal nerve root where the arterial blood from a radiculomeningeal artery enters a radicular vein. The increase in spinal venous pressure leads to decreased drainage of normal spinal veins, venous congestion, and the clinical findings of progressive myelopathy. On MR imaging, the combination of cord edema, perimedullary dilated vessels, and cord enhancement is characteristic. Therapy has to be aimed at occluding the shunting zone, either by superselective embolization with a liquid embolic agent or by a neurosurgical approach. Following occlusion of the fistula, the progression of the disease can be stopped and improvement of symptoms is typically observed.
\end{abstract}

D espite being the most commonly encountered spinal vascular malformation, spinal dural arteriovenous fistulas (SDAVFs) are rare and still underdiagnosed entities, which, if not treated properly, can lead to considerable morbidity with progressive spinal cord symptoms. Because presenting clinical symptoms are unspecific, the neuroradiologist is often the first clinician to raise the possibility of this diagnosis, which initially rests mainly on MR imaging. For a thorough understanding of the disease and for planning the therapeutic strategy, however, selective spinal digital subtraction angiography (DSA) still is necessary. The aim of the following article is to review the epidemiology, etiology, clinical and imaging features, and therapeutic approaches of this type of spinal vascular malformation. Because an understanding of spinal vascular malformations both from an etiologic and pathophysiologic standpoint is based on the spinal vascular anatomy, we will start by briefly describing the salient features of the spine and spinal cord arterial supply and venous drainage followed by a classification of spinal vascular malformations in general and a classification of dural arteriovenous (AV) shunts in particular.

\section{Embryology and Anatomy of the Spinal Vasculature}

Development of the neural plate starts during the third gestational week and is derived from the embryologic ectoderm. This process is induced by the underlying notochord and adjacent mesoderm, which regulate the development of the surrounding structures, including the nerves, blood vessels, and somites. ${ }^{1}$ In this stage, the angioblasts initially form small cell clusters (blood islands) within the embryonic and extraembryonic mesoderm. ${ }^{2}$ Formation of the neural tube begins early in the fourth week (days 22-23) with closure of the rostral and caudal neuropore during days 25-27, which coincides with the establishment of the intrinsic blood vascular circulation

Received November 30, 2008; accepted December 2.

From the Division of Neuroradiology (T.K., S.G.), Department of Medical Imaging, University of Toronto, Toronto Western Hospital and Hospital for Sick Children, Toronto, Ontario, Canada; Clinic for Neuroradiology (T.K.), University Hospital Aachen, Aachen, Germany; Service de Neuroradiologie Diagnostique et Thérapeutique (T.K., S.G.), CHU Le Kremlin Bicetre, Paris, France; and Department of Radiology (S.G.), Ramathibodi Hospital, Mahidol University, Bangkok, Thailand.

Please address correspondence to $\mathrm{T}$. Krings, MD, PhD, University of Toronto, Toronto Western Hospital, UHN, Division of Neuroradiology, 399 Bathurst St, 3MCL-429, Toronto, ON, M5T 2S8, Canada; email: timo.krings@uhn.on.ca

\section{Indicates open access to non-subscribers at www.ajnr.org}

DOI 10.3174/ajnr.A1485 within the spinal cord. ${ }^{3}$ Two longitudinal collector systems form in the subarachnoid space at the dorsal and ventral surface of the cord, later joining the epidural space laterally through numerous bridging or radicular veins. ${ }^{4}$ We propose the term "bridging veins" because these veins do not necessarily follow the spinal nerves as the arteries always do. ${ }^{5}$ This adult-type venous drainage pattern is already seen by the 10 th gestational week. $^{6}$

In the adult, segmental arteries (ie, segmental feeders from the vertebral arteries; the deep and ascending cervical arteries for the cervical levels; intercostal or lumbar arteries at the thoracic and lumbar levels; and, for the sacral levels, the ileolumbar arteries) supply the spine (including the vertebral bodies, paraspinal muscles, dura, and nerve roots) and the spinal cord with blood. ${ }^{7}$ The bony spine is supplied by anterior and posterior central arteries that arise directly from the segmental and radicular arteries. A spinal radicular branch supplying the dura and the nerve root as a radiculomeningeal artery is present at each segment. From these radicular arteries, radiculomedullary arteries might branch, following the anterior or posterior nerve root to reach the anterior or posterior surface of the cord, where they form the anterior or posterior spinal artery. 8

In the adult patient, not all lumbar or intercostal arteries have a radiculomedullary feeder, and their location for a given patient is not predictable. The anterior and posterior spinal arteries constitute a superficial longitudinal anastomosing system. The anterior spinal artery travels along the anterior sulcus and typically originates from the 2 vertebral arteries, whereas the typically paired posterolateral spinal arteries originate from the intradural part of the vertebral artery or from the posterior inferior cerebellar artery (PICA). These 3 arteries run from the cervical spine to the conus medullaris but are not capable of feeding the entire spinal cord. ${ }^{8}$ Instead, they are reinforced from the above-mentioned radiculomedullary arteries, which derive from various (and unpredictable) segmental levels. The best known anterior radiculomedullary artery is the radiculomedullaris magna, (ie, the Adamkiewicz artery). The anterior radiculomedullary arteries branch in a very typical way to reach the spinal cord. The ascending branch continues along the direction of the radicular artery in the midline of the anterior surface. The descending branch, being the larger one at thoracolumbar levels, forms a hairpin curve as soon as it reaches the midline at the entrance of the anterior fissure. ${ }^{9}$ 
The intrinsic network of the spinal cord arteries can be divided into central or sulcal arteries from the anterior spinal artery on the one hand and, on the other, into the rami perforantes of the vasocorona, which supplies the periphery of the spinal cord and is derived from both the anterior and the paired posterolateral arteries. ${ }^{10}$ The venous drainage of the cord is via radially symmetric intrinsic spinal cord veins and small superficial pial veins that open into the superficial longitudinal median anastomosing spinal cord veins. These veins follow more or less the arteries (ie, the anterior and posterior median spinal veins) but have many anastomoses (including transmedullary anastomoses) creating a network with commonly more than 1 anterior and posterior vein. ${ }^{8}$ They may use the roots as a vehicle to reach the epidural plexus and the extraspinal veins and plexus, with a reflux-impeding mechanism within the dura mater. ${ }^{11}$ The transition of a median vein into a radicular vein shows the same hairpin-shape as the artery. At the superior cervical part, these veins can run through the occipital foramen to connect the vertebral plexus to the inferior dural sinuses. Drainage of blood from the spine occurs through the valveless internal and external venous vertebral plexus, connected to the azygos and hemiazygos venous systems.

\section{Classification of Spinal Vascular Malformations in General and Dural AV Shunts in Particular}

Multiple different classification schemes have been proposed for spinal vascular malformations. The Bicetre group classified spinal cord AV malformations into 3 main groups: 1) Genetic hereditary lesions that are caused by a genetic disorder affecting the vascular germinal cells. Spinal cord malformations associated with hereditary hemorrhagic telangiectasia (HHT) fall into this category. ${ }^{12}$ 2) Genetic nonhereditary lesions that share metameric links such as the Cobb syndrome (or spinal AV metameric syndrome), which affects the whole myelomere. ${ }^{13}$ These patients typically present with multiple shunts of the spinal cord; nerve root; bone; and paraspinal, subcutaneous, and skin tissue. Klippel-Trenaunay and ParkesWeber syndromes also belong to this group. 3) Single lesions that may reflect the incomplete expression of one of the previously mentioned situations and include spinal cord, nerve root, and filum terminale lesions. ${ }^{14}$ Because most spinal vascular malformations fall into the last group, we use a classification that is based on the vascular anatomy of the spinal cord as described above. According to this classification, spinal vascular shunting malformations can be differentiated, similar to vascular malformations of the brain, into pial and dural AV shunting lesions depending on the vessels feeding the shunt. ${ }^{15}$

Spinal cord AV malformations are (like their cerebral counterpart) shunts, which are fed by arteries normally supplying the neural tissue (ie, the intrinsic arteries of the spinal cord), whereas SDAVFs (like their cranial counterparts, the dural AV fistulas [DAVFs]) are fed by radiculomeningeal arteries (which are, in fact, similar to meningeal arteries). We will not discuss the pial AV malformations in this review but rather will focus solely on the dural AV shunts, (ie, those shunts that are fed by radiculomeningeal arteries and that lead to a retrograde drainage into the radicular veins toward the perimedullary veins).

In a recent uniform classification of dural AV shunts, ${ }^{5}$ both cranial and spinal AV shunts can be categorized into 3 groups on the basis of the embryologic development of the venous drainage of the surrounding structures: the ventral, dorsal, and lateral epidural groups.

The ventral epidural group consists of shunts into those veins that normally drain structures developed from the notochord (ie, the vertebral body at the spinal level). These veins are known as the basivertebral venous plexus, which subsequently drains into the anterior internal vertebral venous plexus, located at the ventral epidural space of the spinal canal, which joins the basilar venous plexus and cavernous sinus cranially. The previously called "epidural," "osteodural," or "paravertebral" AV shunts can be categorized into this group. Because the draining veins of these shunts do not drain the spine but the bone, these shunts will not become symptomatic due to venous congestion of the cord (Fig 1). Instead they may become symptomatic due to compression of the spinal cord or nerve roots by the enlarged epidural venous pouches. ${ }^{16-18}$ There have been only a few case reports describing associated perimedullary reflux causing congestive myelopathy. ${ }^{11,19}$ A hypothesis about a possible defective valve-like mechanism normally impeding retrograde flow from the epidural plexus to perimedullary veins has been put forward to explain this finding. ${ }^{11}$ However, it may also be argued, that the reflux is due to an extensive thrombosis of the normal epidural outlets that leads to secondary retrograde drainage into the perimedullary veins. ${ }^{5}$

The dorsal epidural group of AV shunts is related to veins that normally drain the spinous process and lamina at the spinal level. Although they are related to the major dural venous sinuses (superior sagittal sinus and torcular and transverse sinuses) at the cranial level, the corresponding veins at the spinal level are poorly developed ${ }^{4}$ and consist of a pair of longitudinal channels (ie, the posterior internal venous plexus). Patients with dural AV shunts within this space typically present with spontaneous epidural hematomas. ${ }^{20,21}$ These shunts are extremely rare.

The most common "classic" types of SDAVFs are the lateral epidural DAVFs. These AV shunts develop in the lateral epidural space at the junction of the bridging (or radicular) veins that connect the spinal cord drainage to the epidural venous system. Outflow obstruction of its adjacent venous outlet, either due to thrombosis or fibrosis related to aging, will then lead to immediate drainage into the perimedullary veins. ${ }^{5}$ As a result, patients within this group present with aggressive clinical symptoms and at an older age. A strong male predominance is also observed, ${ }^{22}$ which is similar to that in the cranially located lateral epidural DAVFs, such as in the foramen magnum (medulla bridging vein) and tentorial (petrosal bridging vein) locations. Below, we will focus only on the latter "classic" form of dural AV shunt of the spine because it represents $>90 \%$ of all spinal dural AV shunts, whereas the remainder are only seldom encountered and, if so, rarely present with clinically significant symptoms.

\section{Epidemiology}

SDAVFs are the most frequent vascular malformation of the spine and account for approximately $70 \%$ of all vascular spinal malformations. ${ }^{23,24}$ An estimation based on the ret- 

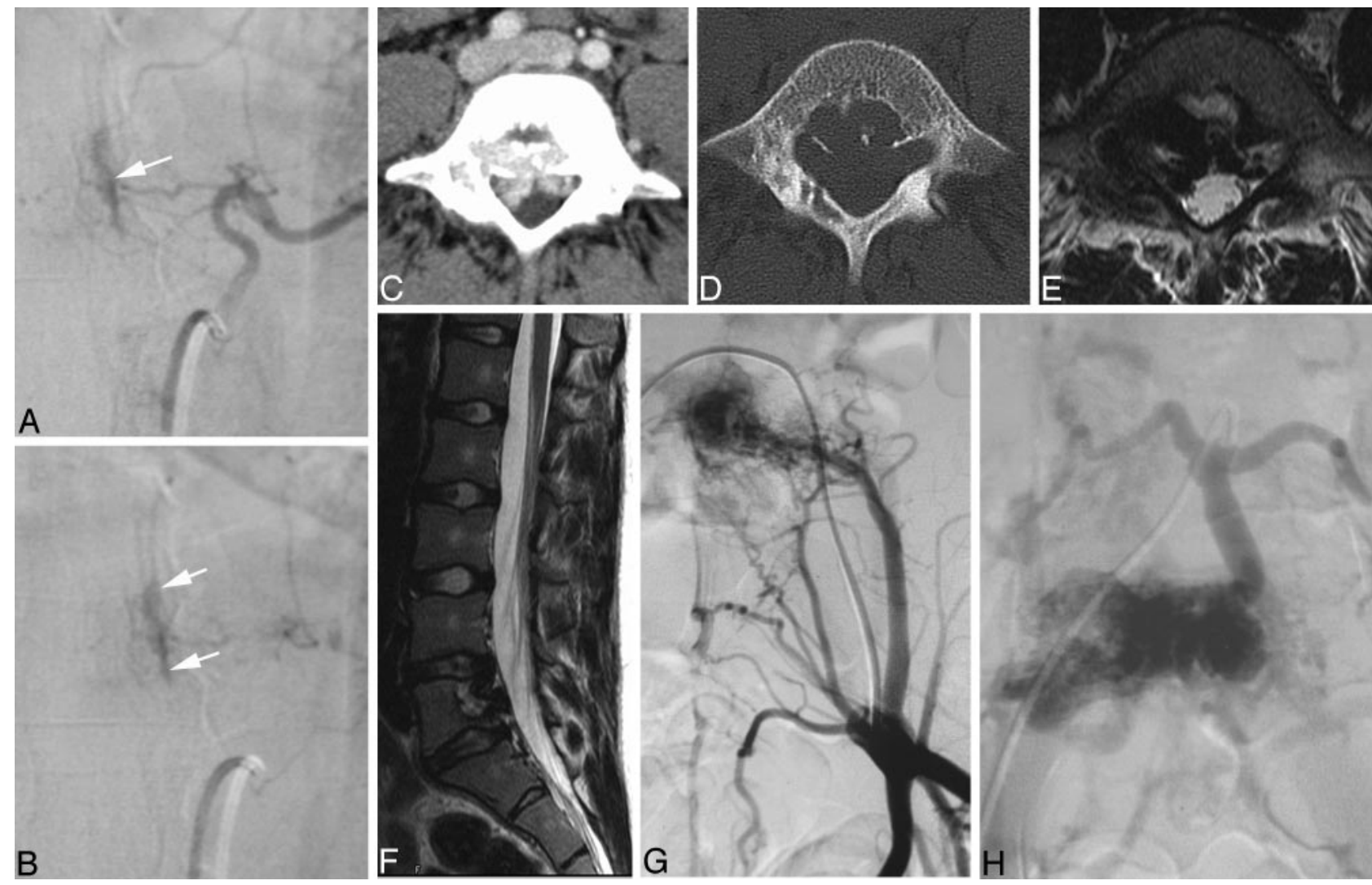

Fig 1. Ventral epidural AV fistulas in 2 different patients. $A$ and $B$, Early and late phases of an injection into a segmental artery with a shunt into the ventral epidural space (white arrows) with no reflux toward the cord. These shunts are classically asymptomatic. $C-H$, Enhanced CT $(C)$, the bone window $(D)$, axial $(E)$ and sagittal $(F)$ T2-weighted scans, and early $(G)$ and late $(H)$ phases of the iliac artery injections in an 18-year-old woman who had constant lumbago for the previous 2 years. A ventral epidural (or osteodural) shunt is demonstrated, which, despite its high-flow nature (usuration of the bone), does not lead to reflux toward the cord because the shunting vessels are related to structures developed from the notochord.

rospective series of the major German referral center for spinal vascular diseases (Prof Thron, Aachen, Germany), arrived at $5-10 /$ million/year in the general population. ${ }^{25}$ However, the disease seems to be underdiagnosed. ${ }^{26,27}$ Usually, SDAVFs become symptomatic in elderly men. A recent meta-analysis ${ }^{22}$ of all series larger than 5 patients concluded that men are affected 5 times more often than women and that the mean age at the time of diagnosis is 55-60 years. Patients younger than 30 years of age constituted less than $1 \%$ of patients with a DAVF, whereas, to our knowledge, no patient younger than 20 years of age has ever been reported. Most fistulas are solitary lesions and are found in the thoracolumbar region. In our experience, $>80 \%$ of all DAVFs are located between T6 and L2. Sacral lesions occur in approximately $4 \%$ of patients, ${ }^{28}$ whereas high cervical lesions (at the level of the foramen magnum) occur in $2 \%$ of patients. ${ }^{29}$ Low cervical DAVFs (below C2 and above $\mathrm{T} 1$ ) are extremely rare. ${ }^{30,31}$ In approximately $2 \%$ of patients, double spinal DAVFs or an association of a spinal dural with a spinal pial AV shunt may be present, raising the possibility of a potential etiologic connection. ${ }^{32,33}$

\section{Etiology and Pathophysiology}

It is presumed that SDAVFs are acquired diseases, though their exact etiology is not known. The AV shunt is located inside the dura mater close to the spinal nerve root where the arterial blood from the radiculomeningeal artery (ie, the artery that supplies the nerve root and meninges but not necessarily the spinal cord) enters a radicular vein, where the latter passes the dura at the dorsal surface of the dural root sleeve in the intervertebral foramen. ${ }^{22}$ This transition is classically located directly underneath the pedicle of the vertebral body, which is supplied by the injected segmental artery. The increase in spinal venous pressure due to arterialization diminishes the AV pressure gradient and leads to a decreased drainage of normal spinal veins and a venous congestion with intramedullary edema because the intramedullary veins and the radicular vein share a common venous outflow. ${ }^{34,35}$ This congestion, in turn, leads to chronic hypoxia and progressive myelopathy. ${ }^{7}$ Direct intraoperative measurement of the vascular pressure of the fistula was found to be as high as $74 \%$ of the systemic arterial pressure. ${ }^{36,37}$ This finding may explain why, in some patients, symptoms become worse during physical activity with a concomitant increase in arterial pressure. ${ }^{38,39}$ Because the lower thoracic region has relatively fewer venous outflow channels compared with the cervical region, ${ }^{40}$ the venous congestive edema is likely to be transmitted in a caudocranial direction throughout the spinal cord. This may explain why the first symptoms of myelopathy sometimes reflect dysfunction of the conus medullaris, even though the shunt is located remotely. ${ }^{41}$

\section{Clinical Features}

Initial symptoms of venous congestion are nonspecific and include difficulty in climbing stairs, gait disturbances, and, 

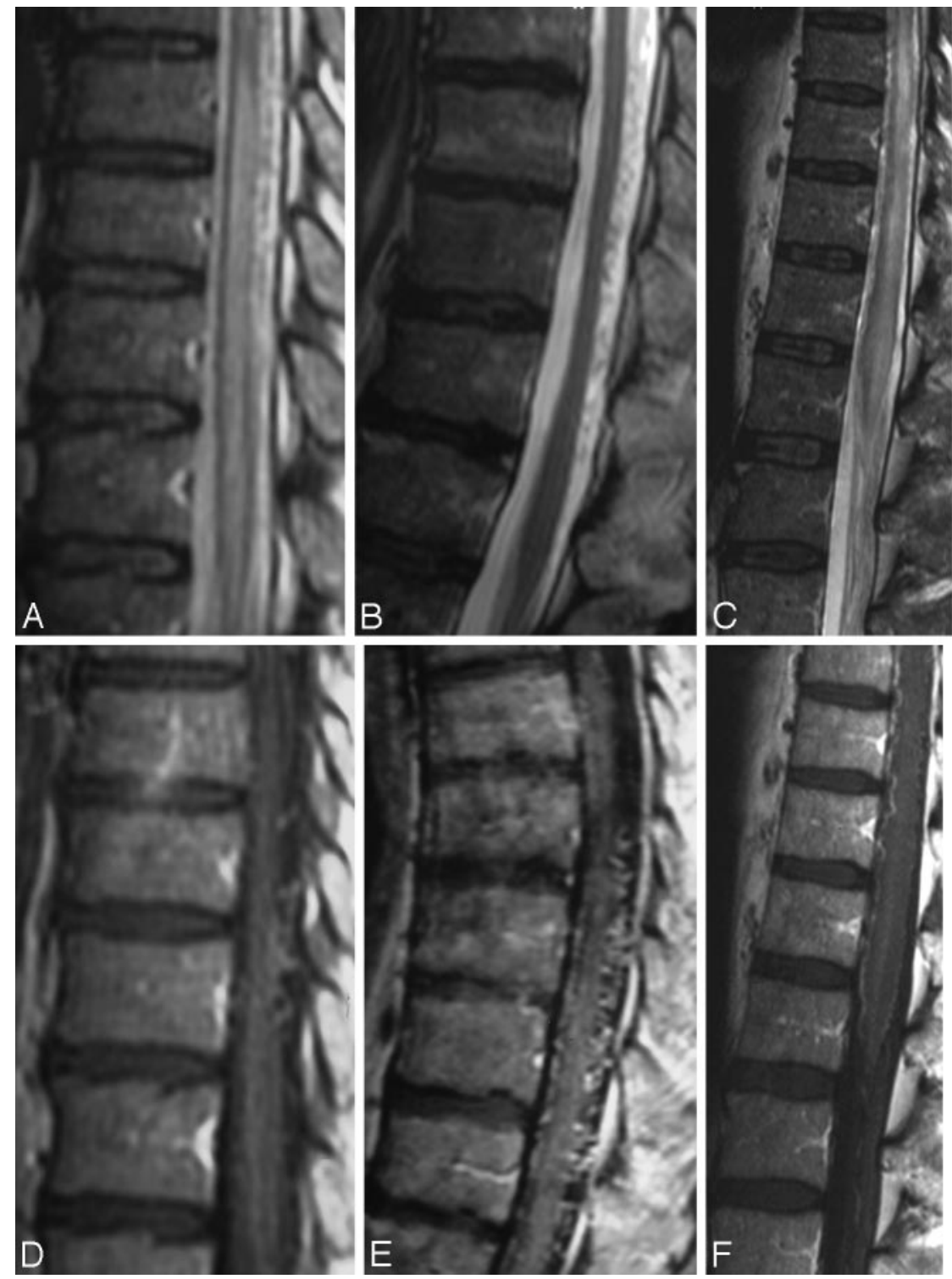

Fig 2. T2-weighted $(A-C)$ and T1-weighted images following contrast enhancement $(D-F)$ in 3 different patients demonstrate the spectrum of characteristic findings of SDAVFs on routine sequences. A centromedullary edema and perimedullary dilated vessels are the hallmark findings. However, even in the absence of edema (B) or in the absence of pathologic vessels on T2-weighted scans $(C)$, the suspicion of an SDAVF is raised due to the coiled vessels seen on T1-weighted scans after contrast enhancement. While a missing edema might indicate a DAVF picked up early in the course of the disease, the missing flow voids on T2-weighted scans indicate a slow-flowing shunt.

more often, sensory symptoms such as paresthesias, diffuse or patchy sensory loss, but also radicular pain that may affect both lower limbs or initially only 1 limb. ${ }^{42}$ Lower back pain without radicular distribution is also frequently encountered. These neurologic symptoms are progressive with time and are often ascending. ${ }^{41}$ Bowel and bladder incontinence, erectile dysfunction, and urinary retention are more often seen late in the course of the disease. Whereas classically the deficits are slowly progressive, an acute onset of the disease and a progressive development interrupted by intermediate remissions are also possible. ${ }^{43}$

A spinal hemorrhage has, in our experience, never occurred and, therefore, rather points toward a perimedullary (ie, pial) shunt rather than a true DAVF. ${ }^{15}$ In rare cases, an SDAVF at the level of the foramen magnum with reflux toward the brain may cause a cranial subarachnoid hemorrhage. ${ }^{44}$ Because the course of the disease is slowly progressive, the neurologic deficits at the time of diagnosis are often considerably worse: Two thirds of patients show a combination of gait difficulty, sensory disturbance, and involvement of sacral segments (micturition, defecation, or sexual dysfunction). ${ }^{42} \mathrm{Up}$ per motoneuron involvement with clonus and positive Babinski signs and lower motoneuron involvement may coexist in the same patient, as has been described in the original observations of Foix and Alajouanine. ${ }^{45,46}$

\section{Imaging Features}

In our experience, the diagnosis rests on MR imaging, is guided by MR angiography (MRA), and is confirmed by DSA. ${ }^{7}$ On T2-weighted sequences, the cord edema is depicted as a centromedullary not well-delineated hyperintensity over multiple segments that is often accompanied by a hypointense rim, most likely representing deoxygenated blood within the dilated capillary vessels surrounding the congestive edema 


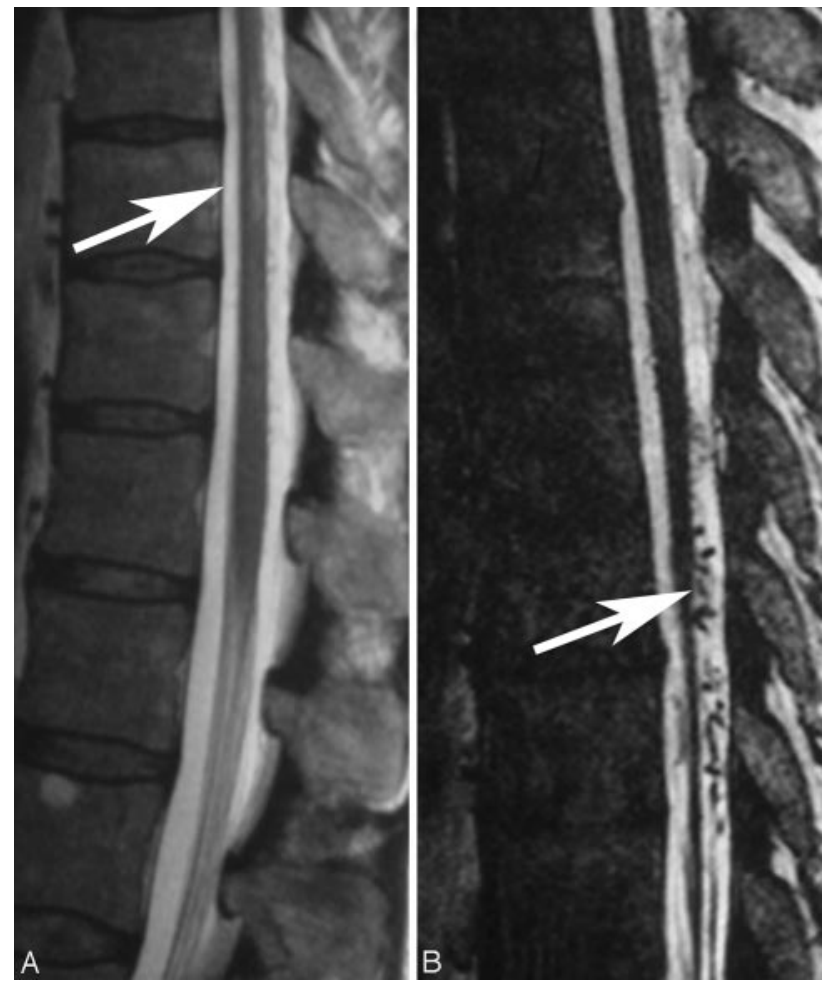

Fig 3. When comparing a routine T2 TSE $(A)$ sequence and a heavily T2-weighted (FIESTA, 3D T2 TSE, or CISS) sequence $(B)$, the former depicts the cord edema better (arrow, $A$ ), whereas the latter is better suited to demonstrate the perimedullary flow voids (arrow, B), as seen in this patient.

(Fig 2). ${ }^{47}$ In the further course of the disease, the cord will become atrophic. ${ }^{48}$ The perimedullary vessels are dilated and coiled and can be observed on the T2-weighted images as flow voids, which are often more pronounced on the dorsal surface compared with the ventral surface. However, if the shunt volume is small, they might only be seen after contrast enhancement (Fig 2). The coiled or serpentine vascular structures may be better appreciated on heavily T2-weighted sequences (constructive interference in steady state [CISS], fast imaging employing steady-state acquisition [FIESTA], or 3D turbo spin- echo [3D-TSE]) compared with standard T2 TSE sequences (Fig 3). ${ }^{7}$ In addition, these sequences may be useful to differentiate pulsation artifacts, which are sometimes mistaken for flow voids, from true vascular tubular structures. Neither the location of pathologic vessels nor the intramedullary imaging findings seem to be related to the height of the fistula. ${ }^{30}$

On T1-weighted scans, the swollen cord is slightly hypointense and enlarged. Following contrast administration, diffuse enhancement may be seen within the cord as a sign of chronic venous congestion with a breakdown of the blood-spinal cord barrier (Fig 4). ${ }^{49,50}$ SDAVFs may occur anywhere from the level of the foramen magnum to the sacrum and localization of these lesions may be difficult and challenging, especially in cases in which cord edema occurs distant from the AV shunt location. ${ }^{51}$ Thus, the noninvasive evaluation of the shunt location is extremely helpful to guide the invasive conventional angiography. ${ }^{52}$ Spinal contrast-enhanced MRA has greatly contributed to localizing these lesions and helping to avoid unnecessary superselective injections of all possible arterial feeders. The technique of first-pass gadolinium-enhanced MRA can clearly demonstrate the early venous filling, thereby confirming the shunt, and, in most cases, can also demonstrate the level of the shunt (Fig 5). ${ }^{53-56}$ Spinal CT angiography has also been shown to demonstrate the fistula localization $^{57}$; however, given the potential location from the foramen magnum to the sacrum, it may lead to a large radiation burden for the patient and, in our experience, does not constitute a practical approach to localizing SDAVFs.

On selective angiography, stasis of contrast material in the radiculomedullary arteries, ${ }^{7}$ especially the anterior spinal artery, can be seen. The delayed venous return following ASA injection indicates venous congestion and underlines the necessity to search for a shunting lesion, whereas in most cases, a normal venous return following injection of the anterior spinal artery (ASA) will exclude the possibility of an SDAVF (Fig 6). ${ }^{30}$ After injection into the segmental artery harboring the AV fistula, the early venous filling and the retrograde contrast uptake of the radiculomedullary veins are visualized. Often an extensive network of dilated perimedullary veins is visible.
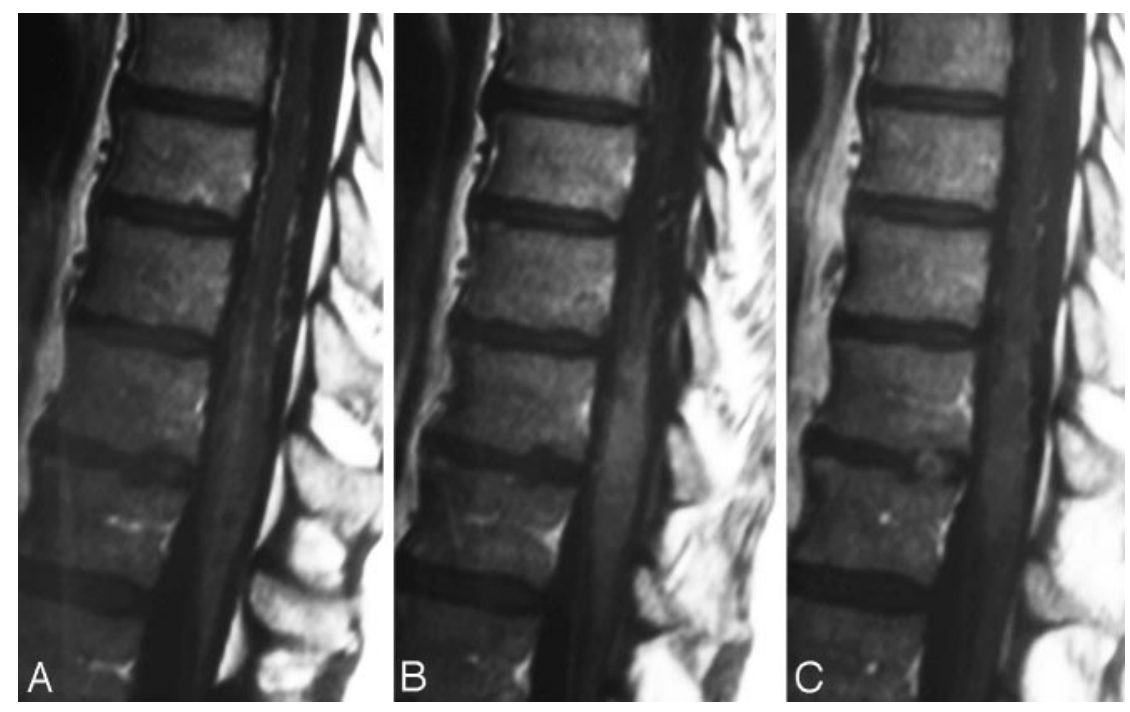

Fig 4. Following contrast enhancement, not only are the dilated perimedullary vessels depicted but sometimes (especially in the later stages of the disease) diffuse enhancement may be seen within the cord as a sign of chronic venous congestion with breakdown of the blood-spinal cord barrier. 

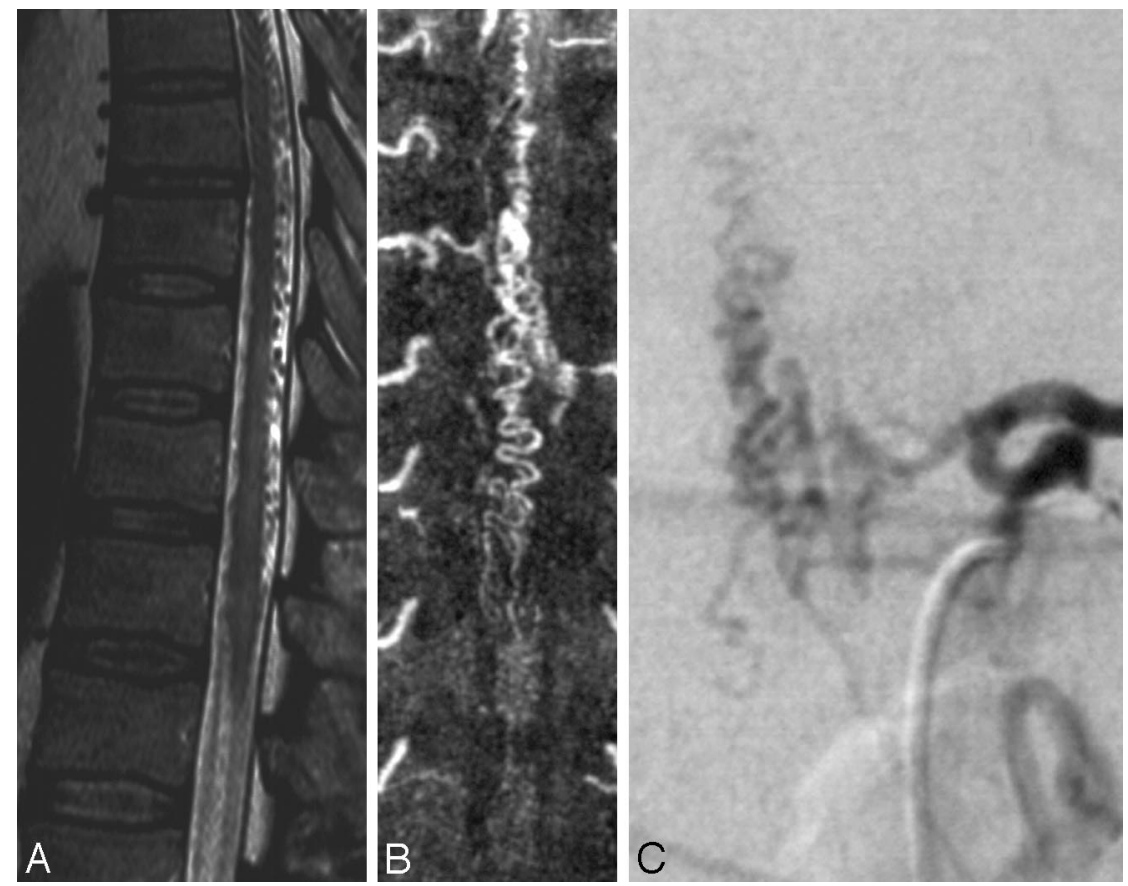

Fig 5. First-pass contrast-enhanced MRA can clearly demonstrate the early venous filling and thereby confirm the presence of a shunt in equivocal cases. $A$ and $B$, On T2-weighted scans $(A)$, the perimedullary flow voids indicate an SDAVF, which is confirmed on coronal spinal MRA $(B) . C$, In addition, as indicated in this patient, MRA helps to demonstrate the level of the shunt, thereby directing the subsequent spinal DSA.
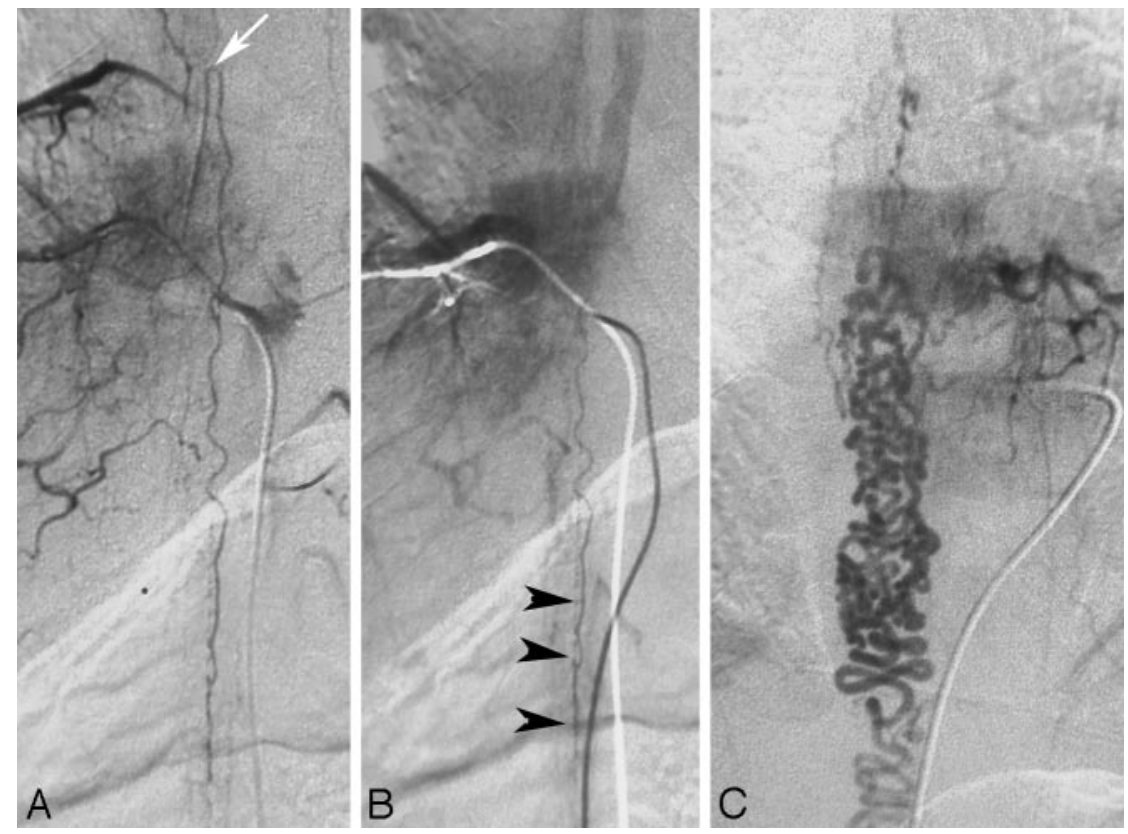

Fig 6. In patients with spinal AV shunts, the venous return after injection into the ASA is delayed due to the arterialized pressure in the spinal cord veins. Therefore, stasis following injection into the segmental artery from which the ASA originates is seen as in this patient. $A$, The arrow demonstrates the hairpin curve of the ASA visible in the early arterial phase. $B$, The late venous phase still demonstrates contrast material within the ASA, which should have been washed out by this time under physiologic conditions (arrowheads). $C$, The reason for the delayed washout is a DAVF at a different level, leading to massive venous congestion.

This network may even recruit supply from dural arteries that ascend or descend from neighboring radiculomeningeal arteries. In rare cases, the flow from the radiculomeningeal artery into the radicular vein may be slow; therefore, we classically perform spinal angiographies to search for DAVFs with a low frame rate (1 image/second) and hold for at least 4 seconds to exclude delayed retrograde filling of the radicular veins.

\section{Differential Diagnosis}

Clinical differential diagnosis of the rather unspecific neurologic symptoms is manifold, including polyneuropathy, tumor, or degenerative disk diseases. ${ }^{22}$ It, therefore, is not surprising that patients with SDAVF see orthopedic surgeons, urologists (urinary retention being misinterpreted as being related to prostrate hypertrophy), ${ }^{58}$ or psychologists (erectile 

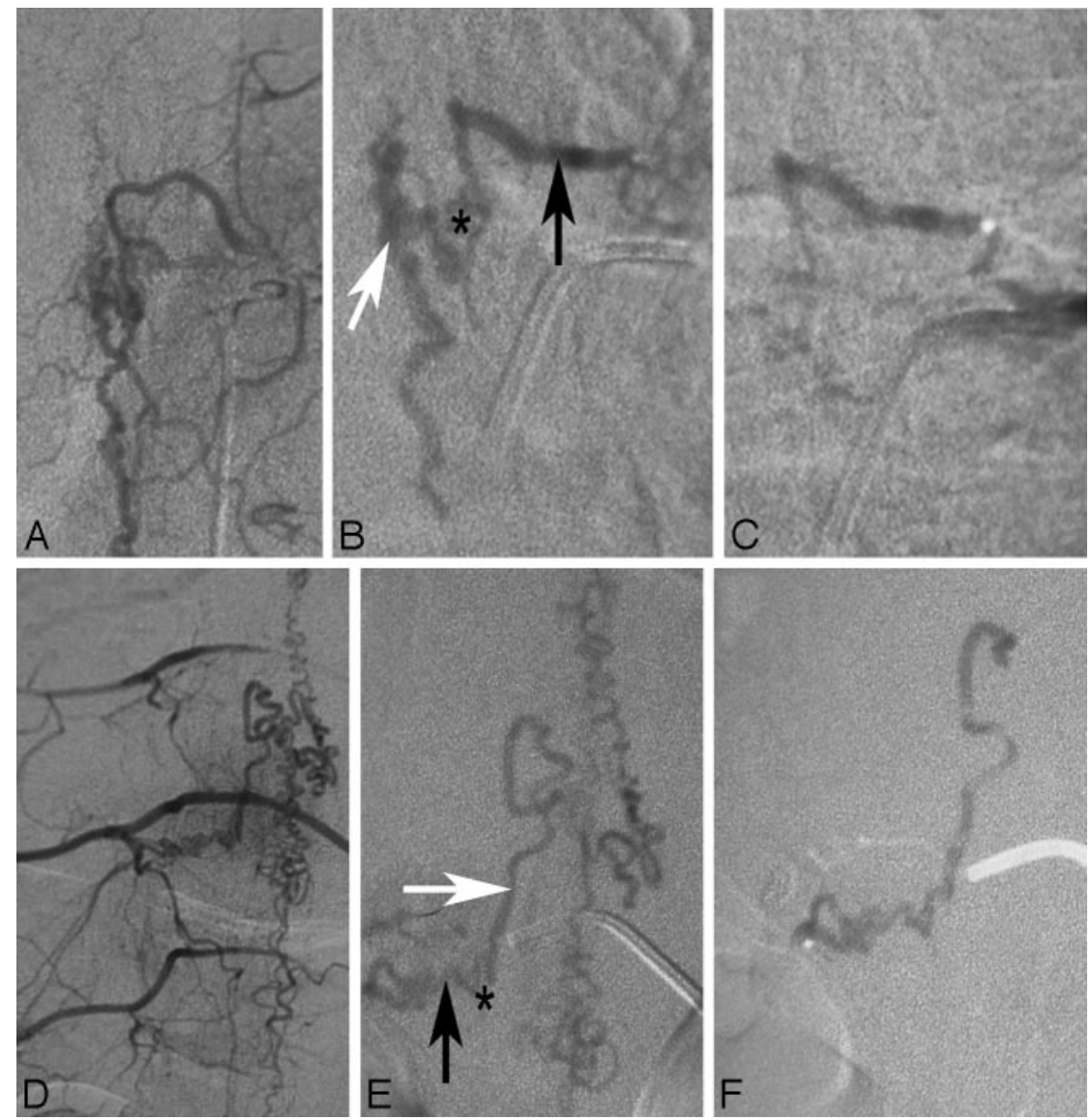

Fig 7. Endovascular therapy in DAVFs in 2 different patients $(A-C$ and $D-F$, respectively). $A$ and $D$ demonstrate the global injections verifying that no supply to the spinal cord is present from the pedicle from which the spinal DAVF is fed. The superselective injections demonstrated on $B$ and $E$ show the feeding artery (black arrow), the shunting zone (asterisk), and the proximal draining vein (white arrow). For an embolization to be effective, the glue has to penetrate from the artery via the shunting zone into the vein. $C$ and $F$, Respective glue casts in both patients: While in the first patient $(C)$ the glue cast did not reach the vein, in the second patient, the glue is visible within the proximal vein. The first patient will necessarily demonstrate recanalization with neurologic deterioration following a period of transient improvement of symptoms, due to the vast collaterals present in the dura, which will reconstitute the fistula. We would, therefore, strongly recommend early surgery (ie, in the same hospital setting). The patient seen in the lower row, though, is completely cured.

dysfunction $)^{59}$ before the neurologist. From an imaging point of view, the MR imaging findings of cord edema together with perimedullary dilated vessels without any intramedullary nidus of vessels are typical for an SDAVF, and the only viable imaging differential diagnosis is another type of spinal vascular malformation. An SDAVF that drains solely into the anterior spinal veins may go along with cord hypersignal on $\mathrm{T} 2$ only because the anterior spinal veins are located subpial and may, therefore, not be visualized as being dilated. ${ }^{60}$ In these cases, a glioma (especially when contrast uptake is present), ${ }^{61}$ an inflammatory lesion, or spinal ischemia should be in the differential diagnosis. ${ }^{7}$

Concerning the DSA appearance, the classic SDAVFs are typically of the slow-flow type, supplied by radiculomeningeal arteries and draining into radicular veins, which directly connect with either ascending or descending perimedullary veins; however, occasionally these angiographic characteristics may be difficult to differentiate from other simulating vascular shunting lesions (ie, radicular AV malformations [rAVMs]; epidural AV shunts, which belong to the ventral and dorsal epidural group of DAVFs; or perimedullary AV fistulas). ${ }^{30}$ rAVMs or AV malformations of the nerves usually have abnormal vessels forming a nidus surrounding the nerve root, whereas SDAVFs have an apparent shunt zone with converging radicular feeders into the same draining vein. These patients also often present with radicular pain and not direct symptoms of congestive venous myelopathy. The ventral and dorsal epidural DAVFs are located in the epidural space and will normally recruit a supply from the vertebral body and surrounding structures, with drainage directly into the epidural plexus and not a perimedullary vein. ${ }^{5}$

Symptoms are related to compression of the adjacent nerve root or cord rather than venous congestion, unless unusual cases of perimedullary reflux occur. ${ }^{51}$ Perimedullary AV fistulas, including fistulas of the filum terminale, are pial shunts at the surface of the cord (or the filum) that are invariably supplied by arteries that, under normal circumstances, would supply the cord (ie, the ASA or the posterior spinal artery). In high-flow shunts, venous pouches are commonly encountered in those vascular malformations, especially in young patients with $\mathrm{HHT}^{12,62}$

\section{Treatment Modalities}

The aim of treatment in SDAVF is to occlude the shunting zone (ie, the most distal part of the artery together with the most proximal part of the draining vein, Fig 7). ${ }^{43,63}$ A proxi- 

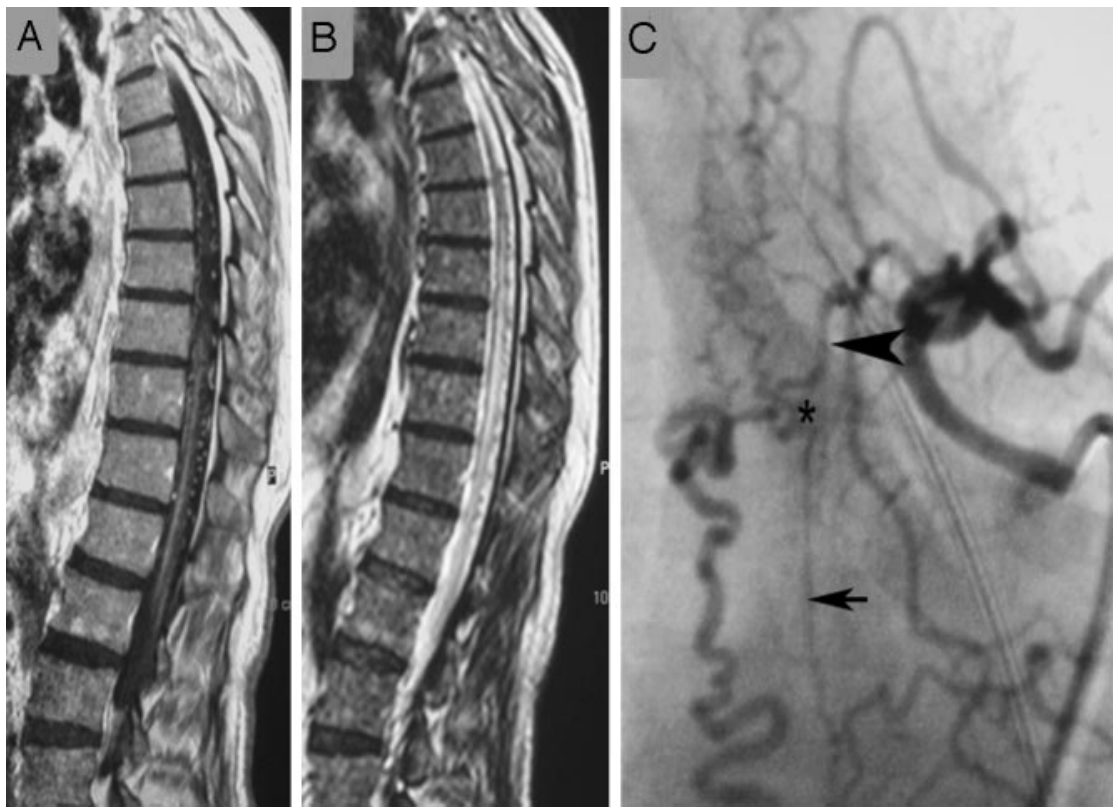

Fig 8. Images of this patient with the classic MR imaging findings of a DAVF on T1-weighted contrast-enhanced $(A)$ and T2-weighted (B) scans demonstrate a vast network of dural collateral arteries in the shunting zone. Although the main supply to the shunt is derived from the radiculomeningeal artery originating from the injected segmental artery (arrowhead), there is an additional supply ascending from a lower segmental artery (small arrow) that is filled via longitudinal collaterals. The shunting zone is denoted by an asterisk. Only if the liquid embolic agent penetrates into the draining veins will this patient be cured; a proximal occlusion will invariably lead to refilling of the shunt via dural collaterals.

mal arterial occlusion will lead to a transient improvement of symptoms; however, owing to the good collateralization of the dura, the fistula is prone to recur within the following months. There are 2 options in the treatment of SDAVFs: surgical occlusion of the intradural vein that received the blood from the shunt zone, a relatively simple and safe intervention with the exception of sacral fistulas ${ }^{64}$; or endovascular therapy using a liquid embolic agent after superselective catheterization of the feeding radiculomeningeal artery. ${ }^{15}$ As pointed out previously, the embolic agent must pass the nidus and reach and occlude the proximal segment of the draining vein to prevent subsequent intradural collateral filling of the fistula (Fig 8). Therefore, proximal occlusions with coils or Gelfoam (Phadia, Uppsala, Sweden) are contraindicated. Embolization with particles is also prone to early recanalization and is, therefore, not indicated. ${ }^{65}$

The success rates of endovascular therapy have been reported to vary between $25 \%$ and $75 \%,{ }^{43,66}$ whereas a recent meta-analysis suggested complete occlusion of the fistula following surgery in $98 \% .{ }^{67}$ If the glue does not reach the venous site, we strongly advocate early surgical intervention because a recent study has shown that patients in whom the endovascular occlusion was incomplete and who required surgical intervention had a bad clinical outcome, which was likely due to the delay of the secondary intervention. ${ }^{68}$ The treatment strategy that is adopted by most centers currently includes a tentative embolization if this is believed to be a safe approach (ie, no spinal cord-supplying artery that may arise from the same pedicle as the feeder to the shunt as present in Fig 9). If the liquid embolic agent penetrates into the vein, long-term clinical follow-up has proved to result in complete obliteration of the fistula and good clinical outcome. ${ }^{69}$ If the glue stays intraarterial, the liquid embolic agent may at least be used to label the feeding artery internally and thereby ease intraoperative fluoroscopic localization of the exact height of the fistula. In the authors' experience, a slow continuous injection of liquid glue (2 parts of iodized oil [Lipiodol; Guerbet, Aulnay-sousBois, France] and 1 part of glue) has a high chance to reach the draining vein and obliterate the fistula.

\section{Prognosis}

Treatment is aimed at halting the progression of the disease, and the prognosis is dependent on the duration of symptoms before treatment and the pretreatment disability. Following complete occlusion of the fistula, the progression of the disease can be stopped in most instances ${ }^{70}$; however, only two thirds of all patients have a regression of their motor symptoms (including gait and strength) and only one third show an improvement of their sensory disturbances. ${ }^{43}$ Impotence and sphincter disturbances are seldom reversible, and pain may persist. In rare cases of long-standing SDAVFs, patients may experience worsening despite complete occlusion. ${ }^{71}$ Still, a deterioration of symptoms after initial improvement should raise the awareness of recanalization of the shunt or a secondary shunt. $^{33}$

\section{Conclusions}

SDAVF is a rare but treatable cause of otherwise progressive paraplegia. The neuroradiologist plays a major role in the detection of these lesions and in their treatment, which should be aimed at occluding the proximal portion of the vein together with the distal arterial segment. Neurologic symptoms are unspecific; however, the MR imaging trias of cord edema, perimedullary vessels, and contrast enhancement of the cord in elderly men should lead to the diagnosis, which should be confirmed by selective DSA, preferably following guidance toward the fistula localization by contrast-enhanced MRA. 

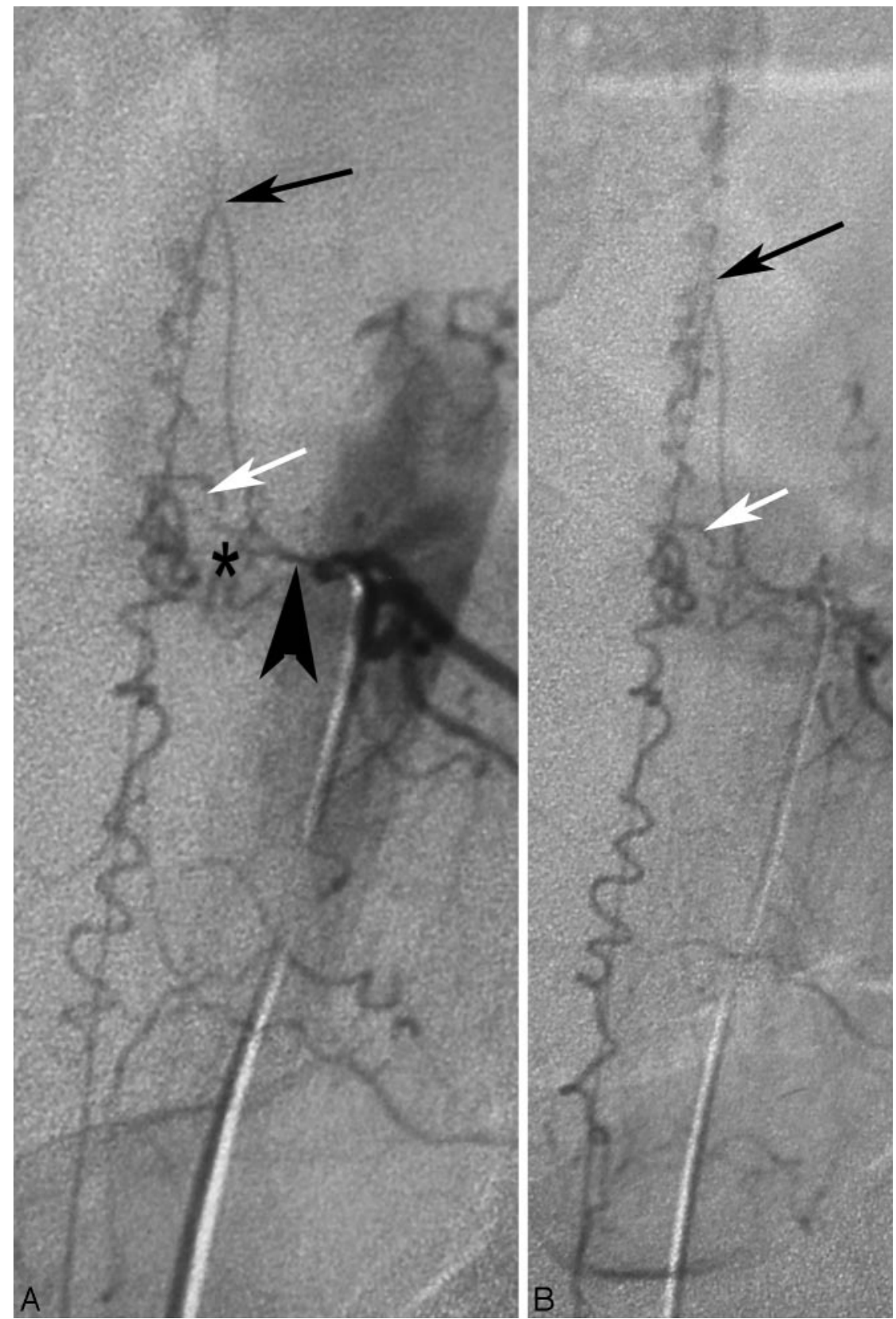

Fig 9. In rare cases, the anterior spinal artery (black arrow) may arise from the same pedicle as the feeder to the shunt (shunting zone, asterisk, draining vein, white arrow). The anterior spinal artery can be identified by the following: 1) its ascending course along the nerve root, 2) its hairpin course at the midline, and 3) the straight course once it reaches the midline of the cord. The vein does not reach the midline via the ascending nerve root but instead via a horizontal and more tortuous course. Embolization in patients with this condition is extremely dangerous, and surgical options may be considered a safer approach.

\section{Acknowledgments}

The authors are indebted to their clinical and neuroradiologic teachers, Drs Armin Thron (Aachen), Sirintara Pongpech (Bangkok) and Pierre Lasjaunias (Paris), to whom we dedicate this article posthumously.

\section{References}

1. Fleming A, Keynes RJ, Tannahill D. The role of the notochord in vertebral column formation. J Anat 2001;199:177-80

2. Eichmann A, Yuan L, Moyon D, et al Vascular development: from precursor cells to branched arterial and venous networks. Int J Dev Biol 2005;49:259-67

3. O'Rahilly R, Muller F. Neurulation in the normal human embryo. Ciba Found Symp 1994;181:70-82, discussion 82-89

4. Groen RJ, Grobbelaar M, Muller CJ, et al. Morphology of the human internal vertebral venous plexus: a cadaver study after latex injection in the 21-25week fetus. Clin Anat 2005;18:397-403
5. Geibprasert S, Pereira V, Krings T, et al. Dural arteriovenous shunts: a new classification of craniospinal epidural venous anatomical bases and clinical correlations. Stroke 2008;39:2783-94

6. Zawilinski J, Litwin JA, Nowogrodzka-Zagorska M, et al. Vascular system of the human spinal cord in the prenatal period: a dye injection and corrosion casting study. Ann Anat 2001;183:331-40

7. Krings T, Lasjaunias PL, Hans FJ, et al. Imaging in spinal vascular disease Neuroimaging Clin N Am 2007;17:57-72

8. Lasjaunias PL, Berenstein A, terBrugge K. Surgical Neuroangiography: Clinical Vascular Anatomy and Variations. Vol 1. Berlin, Germany: Springer-Verlag; 2001

9. Krings T, Geibprasert S, Thron A. Spinal vascular anatomy. In: Naidich T, ed Neuroradiology of the Brain and Spine. New York: Elsevier; 2009. In press

10. Thron A. Vascular Anatomy of the Spinal Cord: Neuroradiological Investigations and Clinical Syndromes. Berlin, Germany: Springer-Verlag; 1988

11. Krings T, Mull M, Bostroem A, et al. Spinal epidural AV fistula with perimedullary drainage: case report and pathomechanical considerations. J Neurosurg 2006;5:353-58 
12. Krings T, Ozanne A, Chng SM, et al. Neurovascular phenotypes in hereditary haemorrhagic telangiectasia patients according to age: review of 50 consecutive patients aged 1 day-60 years. Neuroradiology 2005;47:711-20. Epub 2005 Sep 1

13. Rodesch G, Hurth M, Alvarez H, et al. Classification of spinal cord arteriovenous shunts: proposal for a reappraisal—the Bicetre experience with 155 consecutive patients treated between 1981 and 1999. Neurosurgery 2002;51:374-79

14. Rodesch G, Hurth M, Alvarez H, et al. Angio-architecture of spinal cord arteriovenous shunts at presentation: clinical correlations in adults and children-the Bicetre experience on 155 consecutive patients seen between 19811999. Acta Neurochir (Wien) 2004;146:217-26

15. Krings T, Mull M, Gilsbach JM, et al. Spinal vascular malformations. Eur Radiol 2005; 15:267-78

16. Alexander MJ, Grossi PM, Spetzler RF, et al. Extradural thoracic arteriovenous malformation in a patient with Klippel-Trenaunay-Weber syndrome: case report. Neurosurgery 2002;51:1275-78, discussion 1278-79

17. Kahara V, Lehto U, Sajanti J. Presacral arteriovenous fistula: case report. Neurosurgery 2003;53:774-76, discussion $776-77$

18. Schmidt C, Lonjon J, Costalat V, et al. Paraspinal arteriovenous malformations with perimedullary venous drainage [in French]. J Neuroradiol 2008;35: 165-72. Epub 2008 May 16

19. Silva N Jr, Januel AC, Tall P, et al. Spinal epidural arteriovenous fistulas associated with progressive myelopathy: report of four cases. J Neurosurg Spine 2007;6:552-58

20. Asai J, Hayashi T, Fujimoto T, et al. Exclusively epidural arteriovenous fistula in the cervical spine with spinal cord symptoms: case report. Neurosurgery 2001;48:1372-75, discussion 1375-76

21. Chuang NA, Shroff MM, Willinsky RA, et al. Slow-flow spinal epidural AVF with venous ectasias: two pediatric case reports. AJNR Am J Neuroradiol 2003;24:1901-05

22. Jellema K, Tijssen CC, van Gijn J. Spinal dural arteriovenous fistulas: a congestive myelopathy that initially mimics a peripheral nerve disorder. Brain 2006;129:3150-64

23. Kendall BE, Logue V. Spinal epidural angiomatous malformations draining into intrathecal veins. Neuroradiology 1977;13:181-89

24. Merland JJ, Riche MC, Chiras J. Intraspinal extramedullary arteriovenous fistulae draining into the medullary veins. J Neuroradiol 1980;7:271-320

25. Thron A. Spinal dural arteriovenous fistulas [In German]. Radiologe 2001;41:955-60

26. Grandin C, Duprez T, Stroobandt G, et al. Spinal dural arterio-venous fistula: an underdiagnosed disease? Acta Neurol Belg 1997;97:17-21

27. Jellema K, Tijssen CC, Sluzewski M, et al. Spinal dural arteriovenous fistulas: an underdiagnosed disease - a review of patients admitted to the spinal unit of a rehabilitation center. I Neurol 2006;253:159-62

28. Schaat TJ, Salzman KL, Stevens EA. Sacral origin of a spinal dural arteriovenous fistula: case report and review. Spine 2002;27:893-97

29. Reinges MH, Thron A, Mull M, et al. Dural arteriovenous fistulae at the foramen magnum. J Neurol 2001;248:197-203

30. Geibprasert S, Jiarakongmun P, Krings T, et al. C5-cervical spinal dural arteriovenous fistula presenting with congestive myelopathy of the cone. $\mathrm{J} \mathrm{Neu}$ rosurg Spine 2009. In press

31. Willinsky R, TerBrugge $K$, Lasjaunias $P$, et al. The variable presentations of craniocervical and cervical dural arteriovenous malformations. Surg Neurol 1990;34:118-23

32. Krings $\mathrm{T}$, Coenen VA, Weinzierl M, et al. Spinal dural arteriovenous fistula associated with a spinal perimedullary fistula: case report. J Neurosurg Spine 2006;4:241-45

33. Krings T, Mull M, Reinges $\mathrm{MH}$, et al. Double spinal dural arteriovenous fistulas: case report and review of the literature. Neuroradiology 2004;46:238-42

34. Kataoka H, Miyamoto S, Nagata I, et al. Venous congestion is a major cause of neurological deterioration in spinal arteriovenous malformations. Neurosurgery 2001;48:1224-29, discussion 1229-30

35. Hurst RW, Kenyon LC, Lavi E, et al. Spinal dural arteriovenous fistula: the pathology of venous hypertensive myelopathy. Neurology 1995;45:1309-13

36. Hassler W, Thron A. Flow velocity and pressure measurements in spinal dural arteriovenous fistulas. Neurosurg Rev 1994;17:29-36

37. Hassler W, Thron A, Grote EH. Hemodynamics of spinal dural arteriovenous fistulas: an intraoperative study. J Neurosurg 1989;70:360-70

38. Aminoff MJ, Barnard RO, Logue V. The pathophysiology of spinal vascular malformations. J Neurol Sci 1974;23:255-63

39. Khurana VG, Perez-Terzic CM, Petersen RC, et al. Singing paraplegia: a distinctive manifestation of a spinal dural arteriovenous fistula. Neurology 2002;58:1279-81

40. Tadie M, Hemet J, Freger P, et al. Morphological and functional anatomy of spinal cord veins. J Neuroradiol 1985;12:3-20

41. Koenig E, Thron A, Schrader V, et al. Spinal arteriovenous malformations and fistulae: clinical, neuroradiological and neurophysiological findings. J Neurol 1989;236:260-66
42. Jellema K, Canta LR, Tijssen CC, et al. Spinal dural arteriovenous fistulas: clinical features in $\mathbf{8 0}$ patients. J Neurol Neurosurg Psychiatry 2003;74:1438-40

43. Van Dijk JM, TerBrugge KG, Willinsky RA, et al. Multidisciplinary management of spinal dural arteriovenous fistulas: clinical presentation and longterm follow-up in 49 patients. Stroke 2002;33:1578-83

44. Kai Y, Hamada J, Morioka M, et al. Arteriovenous fistulas at the cervicomedullary junction presenting with subarachnoid hemorrhage: six case reports with special reference to the angiographic pattern of venous drainage. AJNR Am J Neuroradiol 2005;26:1949-54

45. Foix $\mathrm{CH}$, Alajouanine $\mathrm{T}$. La myelite necrotique subaigue. Rev Neurol 1926;46:1-42

46. Schrader V, Koenig E, Thron A, et al. Neurophysiological characteristics of spinal arteriovenous malformations. Electromyogr Clin Neurophysiol 1989;29:169-77

47. Gilbertson JR, Miller GM, Goldman MS, et al. Spinal dural arteriovenous fistulas: MR and myelographic findings. AJNR Am J Neuroradio 1995;16:2049-57

48. Huffmann BC, Spetzger U, Reinges M, et al. Treatment strategies and results in spinal vascular malformations. Neurol Med Chir (Tokyo) 1998;38(suppl):231-37

49. Chen CJ, Chen CM, Lin TK. Enhanced cervical MRI in identifying intracranial dural arteriovenous fistulae with spinal perimedullary venous drainage. $\mathrm{Neu}$ roradiology 1998;40:393-97

50. Terwey B, Becker H, Thron AK, et al. Gadolinium-DTPA enhanced MR imaging of spinal dural arteriovenous fistulas. J Comput Assist Tomogr 1989;13:30-37

51. Bostroem A, Thron A, Hans FJ, et al. Spinal vascular malformations: typical and atypical findings. Zentralbl Neurochir 2007;68:205-13. Epub 2007 Oct 26

52. Bowen BC, Fraser K, Kochan JP, et al. Spinal dural arteriovenous fistulas: evaluation with MR angiography. AJNR Am J Neuroradiol 1995;16:2029-43

53. Farb RI, Kim JK, Willinsky RA, et al. Spinal dural arteriovenous fistula localization with a technique of first-pass gadolinium-enhanced MR angiography: initial experience. Radiology 2002;222:843-50

54. Mull M, Nijenhuis RJ, Backes WH, et al. Value and limitations of contrastenhanced MR angiography in spinal arteriovenous malformations and dural arteriovenous fistulas. AJNR Am J Neuroradiol 2007;28:1249-58

55. Bowen BC, Pattany PM. Contrast-enhanced MR angiography of spinal vessels. Magn Reson Imaging Clin N Am 2000;8:597-614

56. Bowen BC, Saraf-Lavi E, Pattany PM. MR angiography of the spine: update. Magn Reson Imaging Clin N Am 2003;11:559-84

57. Yamaguchi S, Eguchi K, Kiura Y, et al. Multi-detector-row CT angiography as a preoperative evaluation for spinal arteriovenous fistulae. Neurosurg Rev 2007;30:321-26, discussion 327

58. Sheikh SI, Busl KM, Ning M, et al. Spinal dural arteriovenous fistula mimicking prostate hyperplasia. J Emerg Med 2008 Nov 18. [Epub ahead of print]

59. Jellema K, Tijssen CC, van Rooij WJ, et al. Spinal dural arteriovenous fistulas: long-term follow-up of 44 treated patients. Neurology 2004;62:1839-41

60. Thiex R, Mayfrank L, Krings T, et al. Delayed diagnosis of spinal dural arteriovenous fistula in the absence of pathological vessels on MRI. Zentralbl Neurochir 2006;67:94-98

61. Roccatagliata L, Centanaro F, Castellan L. Venous congestive myelopathy in spinal dural arteriovenous fistula mimicking neoplasia. Neurol Sci 2007;28:212-15

62. Krings T, Chng SM, Ozanne A, et al. Hereditary hemorrhagic telangiectasia in children: endovascular treatment of neurovascular malformations-results in 31 patients. Neuroradiology 2005;47:946-54

63. Jellema K, Sluzewski M, van Rooij WJ, et al. Embolization of spinal dural arteriovenous fistulas: importance of occlusion of the draining vein. J Neurosurg Spine 2005;2:580-83

64. Huffmann BC, Gilsbach JM, Thron A. Spinal dural arteriovenous fistulas: plea for neurosurgical treatment. Acta Neurochir (Wien) 1995;135:44-51

65. Nichols DA, Rufenacht DA, Jack CR Jr, et al. Embolization of spinal dura arteriovenous fistula with polyvinyl alcohol particles: experience in 14 patients. AJNR Am J Neuroradiol 1992;13:933-40

66. Niimi Y, Berenstein A, Setton A, et al. Embolization of spinal dural arteriovenous fistulae: results and follow-up. Neurosurgery 1997;40:675-82, discussion $682-83$

67. Steinmetz MP, Chow MM, Krishnaney AA, et al. Outcome after the treatment of spinal dural arteriovenous fistulae: a contemporary single-institution series and meta-analysis. Neurosurgery 2004;55:77-87, discussion 87-88

68. Andres RH, Barth A, Guzman R, et al. Endovascular and surgical treatment of spinal dural arteriovenous fistulas. Neuroradiology 2008;50:869-76

69. Sherif C, Gruber A, Bavinzski G, et al. Long-term outcome of a multidisciplinary concept of spinal dural arteriovenous fistulae treatment. Neuroradiology 2008;50:67-74

70. Aghakhani N, Parker F, David P, et al. Curable cause of paraplegia: spinal dural arteriovenous fistulae. Stroke 2008;39:2756-59

71. Cenzato M, Versari P, Righi C, et al. Spinal dural arteriovenous fistulae: analysis of outcome in relation to pretreatment indicators. Neurosurgery 2004;55: 815-22, discussion 822-23 